This is an Accepted Manuscript of an article published by Taylor \& Francis in Gender, Place \& Culture online $3^{\text {rd }}$ March 2015, available online:

http://wwww.tandfonline.com/10.1080/0966369X.2015.1013439 
Being seen in your pyjamas: The relationship between fashion, class, gender \& space

Katherine Appleford

Kingston University London - Criminology and Sociology

Penrhyn Road Surrey, Kingston Upon Thames KT1 2EE

United Kingdom

Email: k.appleford@kingston.ac.uk

Word count: 10732 (no figs)

$\mathrm{CN}$ : yes

Ackn: no 


\section{Being seen in your pyjamas: The relationship between fashion, class, gender \& space}

Over the last decade class has re-emerged as a significant concept within British sociology, with prominent academics calling for a more Bourdieuian approach which focuses on class distinctions in cultural practices and tastes. Within this discussion, several note the important role fashion plays as a means of class distinction, though few have fully explore just how the fashion-class relationship operates.

Based on empirical research, carried out as part of qualitative study into fashion practices and fashion discourse, this article examines the fashion-class relationship, by considering its links to both gender and space. It argues that the way in which women judge visibility and public space differs with class status and that this in turn has significant implications for women's fashion choices, and more specifically, dressing up.

Indeed, whilst middle class participants tend to view almost any space as public and one in which they are visible, for working class participants neighbourhood and local spaces are seen to constitute semi-private spaces, whose audiences' opinions and judgements do not matter. As a result, being dressed in your pyjamas is not deeply problematic for these working class women in the context of their everyday lives, while for their middle class counterparts being seen in your pyjamas is something which should be avoided, at all cost. Moreover, as the article demonstrate, the wearing of pyjamas is often considered by middle class respondents as indicative of working classness. And thus, being seen in your pyjamas is undesirable on two counts.

Keywords: Class; Gender; Fashion; Performance; Space; Visibility

\section{Introduction}

The purpose of this article is to consider class distinctions in women's everyday practices of dressing up and to highlight class' role in informing women's understandings of public space and visibility, and the need for a performance. Bringing together class, fashion, gender and space, the article suggests that women's concerns over being seen is influenced and informed by their class location, and that this anxiety fuels the need for a performance and some form 
of dressing up. In this way, class mobilise particular fashion practices and at the same time creates class distinctions, for whilst some women tend to consider any public space as a space in which they are visible or seen and thus as space in which they should dress up, for others, local and neighbouring spaces are to a greater extent considered private spaces, and are spaces into which backstage performances can be extended.

The article draws on a qualitative study, which examined how class is mobilised and evaluated though fashion discourses and practice, conducted at a time when there was much discussion over what forms of dress where suitable for public spaces. In particular, questions were raised over the appropriateness of pyjamas when supermarket shopping, and although the research did not specifically focus on the fashion-space relationship or the wearing of pyjamas, there was clearly a difference in attitudes amongst participants when it came to being seen in your pyjamas.

The article focuses on three key areas, the first of which explores the association between dressing up and public spaces. Drawing on historical and contemporary literature, it sets out the distinction between public and private space, arguing that the public space is a space of display, and one in which fashion communicates social identities. Highlighting the added aspect of visibility, it notes the degree to which women feel scrutinised by others in these spaces, and how this again, influences fashion practices and dressing up.

The next section offers a closer examination of the attitudes and practices displayed more by middle class women in this research. It discusses the anxiety these women commonly express over the judgements others may make of them, and notes the associations made between working classness and falling below 'proper' standards. As the section focuses heavily on the relationship between class and visibility, it draws particularly on the work of Bourdieu (2005 [1984]), as he provides a useful discussion of pretension and performance, and further acknowledges fashion's relationship to visibility and class evaluations, a 
relationship somewhat overlooked in others' discussion of gender, such as Butler (1990) or Tseëlon (1992; 1995).

In the subsequent, and final section, the discussion turns to participants' understanding of space visibility, and performance. It considers the way in which backstage performances are extended to local and familiar spaces such as the supermarket and it notes the way in which motherhood is seen to eliminate the obligation to dress up, for many of the working class participants. That is not say that these women never dress up. Far from it. Dressing up is an important practices for them, but it is one which takes place when 'going out' to public spaces where they are much more likely to encounter strangers and therefore feel subject to scrutiny.

\section{Bringing fashion, class gender \& space together}

Though in more recently years authors have explored fashion's relationship with identity and with space (e.g Barnard, 2010; Breward and Gilbert, 2006; Entwistle, 2000, 2001, 2009; Rocamora, 2009), the way in which this relationship is influenced and effected by class is often overlooked (xxxx, 2012). At the same time, contemporary discussions of space, gender and class (e.g. McDowell, 1997; 2008; Taylor, 2012) have tended not to focus particularly on the role that fashion plays. Yet, historically, the relationship between fashion, class, gender and space has been an important aspect of fashion theories.

In the traditional work of Simmel (2004 [1901]) and Veblen (1999 [1899]), fashion is seen as the innovation of the upper classes and its adoption is driven by a desire for social mobility. Worn predominately by women as a public display of wealth and status, fashion is read as a sign of respectability and social identity (Finch, 1993) and 'affords an indication of our pecuniary standing to all observers at first glance' (Veblen, 1994 [1899]: 103). As such, it 
operates as a marker of class and status, but it also helps to define the space as public or private.

Indeed, it is 'through materially embedded practices' (Massey, Allen and Sarre, 1999: 246), such as fashion, that spaces and spatial distinctions are made, and re-made. Filled with 'people, practices, objects and representations' (Gieryn, 2000: 465), space is not fixed, but is, as Gillian (1999: 248) suggests, an active process or 'doing'. Whether public or private, space is constituted through social and cultural practices and performances (Bell, et, al., 1994; Cresswell, 2004), and it is understood in relation to other spaces and other interactions or practices (Löw, 2006; Valentine, 2001).

And it is not just space which is 'made'. An embodied practice, class is also a 'way of living' (McDowell, 2008: 21), negotiated across time and space, and evaluated and performed through individuals' every day practices and social interactions (McDowell, 2006: 216). The food that we eat and the way that we eat it, the places we visit, the literature that we read, the music we listen to (Bennett et al., 2010), in fact the most 'automatic of gestures or apparently most insignificant techniques of the body' (Bourdieu, 2005 [1984]: 466) all operate as markers of class and are used to evaluate and place people within the social space and class hierarchy.

Fashion brings class and space together. As Potvin (2009: 9) argues, 'fashion is one of those ways we understand our place in the world'; it works to locate us in a social hierarchy, and it conveys our understandings of a social space. It 'provides one of the most ready means through which individuals make expressive visual statements about their identities' (Bennett, 2005: 103). It operates as a symbolic marker of taste, and thus a marker of class (Bourdieu, 2005 [1984]). And, at the same time, it is a 'situated' practice which helps to define the space as public or private (Potvin, 2009; Tseëlon, 1995), as a space in which we are 'visible' and 
thus scrutinised by others (Sennett, 2003 [1974]) or an intimate space 'under the control of the individual in a personal capacity' (Madanipour, 2003: 230).

\section{Context of this study}

The study focused on the ways in which class is mobilised through fashion discourse and fashion practices and tastes, and how fashion is used in class evaluations. As fashion still tends to be identified as a feminine pursuit (De Grazia and Furlough 1996), the study centred on women, and took a qualitative approach employing interviews and observations. In total 53 women took part in the research. Participants were aged between 18 and 70, the average age being 38; 8 were from Black and Ethnic Minority backgrounds and 35 were as middle class, 18 were working class.

I decided to evaluate the class location of the participants on the basis of selfdefinition and demographic information such as: housing, occupation, education, partner's and parents' occupations, which have been traditionally used by sociologists to assess socioeconomic status (e.g. Lawler, 2000; Skeggs et al., 2008; Walkerdine et al., 2001).Though self-classification is a subjective measure and can result in participants mostly defining themselves as middle class (Tan, 2004), in this project there was generally a good fit between the women's classification and their forms of capital ${ }^{1}$. Indeed, the majority of participants classified themselves on the basis of their education, income and/or housing,

Kelly: People like me, we live on council estates, with loads of kids and families.

$\mathrm{XX}$ : So if I asked you what class you were, what would you say?

Kelly: Working class. I think, yeah ... We're not poor, we're just, the money we have we live on it... [Aged 18, Unemployed]

However, as Skeggs' et al. (2008: 8) found, some working class participants, three in this instance, 'struggled to easily locate a class position' opting to instead dis-identify from being middle class as they did not considered themselves 'posh' or 'rich'. And, there was also 
less certainty from three women who felt they had come from 'working class backgrounds' (due to their parents' occupations or housing tenure) but who now consider themselves to be middle class, based on their occupations and home ownership.

The challenge of making classification have been noted by a number of authors. As Savage (2000: 37) argues, individuals are likely to discuss class as a political issue 'out there' rather than as a personal attribute, because questions of class can raise 'issues of relative worth' (Sayer, 2002: 1.2). Indeed, in this research women often talked about class in relation to others, situating themselves through a process of distancing. But, when asked directly about which class 'they belonged to', most responded positively, though they occasionally made use of 'moderating terms' (Savage, et al. 2001) such as 'I guess' or 'I suppose'.

Though the salience of class in western societies has been heavily questioned, particularly between 1980-1990 (Smith, 2000), over the last fifteen years authors such as Crompton (1998; 2008), Devine, et., al. (2005), Savage et, al. (2013) and Skeggs (2004a; 2004b) have convincingly argued for its continued relevance in the UK today. Adopting Bourdieu's (2005 [1984]) concept of class, these authors suggest that it is through our consumption habits and cultural tastes that class distinctions are made, and that these forms of class evaluations are still prevalent in British culture.

For Bourdieu class is not only determined by economic capital or wealth, but cultural and social capital too. Together these three types of capital, along with our experiences, form our 'habitus': 'a system of durable, transposable dispositions' and 'principles, which generate and organise practices and representations' (1990: 53). It is through these dispositions that class distinctions are drawn. As Bourdieu argues, 'they become signs of distinction, they function as symbolic capital,' (136) and they operate as a means of classification. Thus class is not simply an occupational or economic category, but an action and embodiment (McDowell, 2008; Skeggs, 2004a) made evident through our cultural and social practices and 
tastes, such as those in fashion. Indeed, as Simmel argues 'fashion is a product of class distinction' (2004 [1901]: 291) and throughout this study, there was evidence of class differences in terms of women's fashion practices, tastes and buying criteria, and fashion was often employed by participants when making class evaluations.

\section{Fashion and public performance}

For all of the participants 'dressing up' tends to be the aspect of fashion which they are most keen to discuss, and often in the context of special occasions such as weddings, and in relation to restaurants and nightclubs. These are places where participants feel it necessary to 'put more effort' into what they are wearing and they spend more time thinking about their outfits asking others for advice. But for some women, dressing up is not restricted to these special occasions or venues. In fact, for middle class respondents it seems that dressing up is associated with any space beyond the personal and intimate boundaries of their own home, or spaces in which they encounter those other than close family. Though the type of dressing up still depends somewhat on the spatial, social and temporal context, the practice of dressing up is routine and conducted in relation to work, the school run and the weekly shop.

Miriam: There's different types of smart really, there's smart in the sense of smart for work, and for me that would be like, no trainers, black trousers, ... maybe like a tank top over the shirt... smart in terms of going to dinner...would probably be like a dress... but if I'm on my own or with my husband, then there is no smart. But if I just go shopping by myself I'm trying to wear more uncomfortable clothes. They're not really that uncomfortable but I'm trying to be more my kind of smart. [Aged 28, GP]

Whether it takes place in the context of the everyday or special occasions dressing up has two key features. Firstly, it is about dressing for 'public' spaces; and secondly it is concerned with being 'visible' and thus being scrutinised by others (Sennett, 2003 [1974]; Tseëlon, 1995). As Lynch and Strauss (2007: 104) argue the dressed body is about making a 
performance, 'dressing for others to see' and 'putting on a show for the benefit of others' (Goffman, 1990 [1959]: 28). Much more than simply the clothes that we wear, fashion within a modern society is a cultural phenomenon (Barnard, 2010: 5); the embodiment of shared meanings, attitudes and values, and the 'insignia by which we are read and come to read others' (Entwistle, 2001: 47).

Indeed, since the industrial revolution, fashion has been used to convey the wealth and status, gender, age, personality and leisure pursuits of the individual (Wilson, 2007 [1985]). From the 1800s onwards, the city operated as a public space which existed 'outside the boundaries of individual or small group control' and involved 'contract and exchange amongst strangers' (Madanipour, 2003: 232-3). Unlike the home, or private space, which 'protected the individual from the general gaze' (Nagel, 1998: 5) and where the self could 'be expressed outside of social roles' (Saunders, 1990: 33), the public realm was a stage or theatre for social performance. A space of social spectacle, consumption and leisure (Walkowitz, 1992), the city was 'characterised by continuous flux and frequent encounters with strangers' (Nava, 1996: 39). Cosmopolitan and diverse, 'depersonalised' and 'anonymous' (Sennett, 2003 [1974]: 137) it was a place where people progressively distanced themselves from each other, and was characterised by unfamiliarity (Simmel, 1971 [1903]).

In this new urban setting fashion had what Thomas Carlyle describes as 'unspeakable significance' (Gunn, 2007: 158) as it was the only mechanism for evaluating and placing people who were otherwise unknown. Small details such as the 'cut of a coat or the shape of a pairs of boots' (2007: 158), decorative lace frills, or a gentleman's buttons, became important markers of social standing (Sennett, 2003 [1974]: 162), whilst at the same time an individual's clothing could act as a mask or armour against the constant gaze of the crowd (Madanipour, 2003) and the intensity of the metropolis (Simmel, 1971 [1903]). 
Today, public space is still defined in relation to the private and is considered to be a space in which people are linked through polity, rather than close, intimate ties of kin or kith (McDowell, 1999: 103). Not restricted simply to city spaces, public space is considered to be any interpersonal or impersonal space, operating 'beyond the personal realm of individuals and their intimate circle of friends and family' (Madanipour, 2003: 110). A realm of sociability, where interactions and encounters take place with acquaintances, colleagues and strangers, it is often considered to be the space outside of the home, but can equally exist inside of the house with the entry of a stranger or visitor (Ardener, 1997). Indeed, rather than being 'bounded, fixed or stable' (Valentine, 2001: 8) public space exists as a continuum, with some spaces being more or less public than others.

All public spaces are however, in some way concerned with the performance of identity (Hetherington, 1998), and one of the key ways in which identity is still constituted, is through fashion (Barnard, 2010). Used to construct a 'natural' appearance, or 'idealised self' (Woodward, 2007), fashion operates as a mask for the individual to hide behind, forming an important part of the 'performing self' (Featherstone, 1991: 187), even in ordinary contexts. As Madanipour (2003: 119) suggests, the 'masks we wear to face others are usually made of normal routines... from changing clothes to shaving or putting on makeup...This is not preparation for a special occasion. It is just a routine social habit of human beings in their daily social life' and forms part of our everyday performance and management of our personal front (Goffman, 1990 [1959]; Nagel, 1998).

The notion that fashion is a mask is made evident in the comments from Penny, particularly when discussing fashion in the context of work. An interpersonal public space, work is a space in which women construct and perform an identity through fashion (McDowell, 1997; Entwistle, 1997; 2000). Women 'dress the body for work' (McDowell, 
1997: 145) they adjust their appearance in order to 'blend in' or as Penny suggests, they use clothes to 'hide behind' and 'play the part'.

Penny: At work, you can wear whatever you want, but I decided to go in a bit smarter so that they might think I've got more money, or that I am better at my work ... You've got to dress the part, so if I dress like an Art Director then I might get a job as an Art Director ... it's a very easy thing to do, really. So even if I can't do the work, I look the part, and that's something. [Aged 31, Art Director, Advertising]

As Entwistle argues, dress is an 'important aspect in the management and discipline of bodies within the work place' (1997: 316) and women, like Penny, consciously calculate their 'self-presentation ... in order to produce an image which shows ... commitment to the life (and lifestyle) of an executive' (319). In these spaces women use their clothing such as tailored jackets or 'variant[s] of the male business dress' to 'blend in with their male peers' (McDowell, 1997: 146), visibly 'bestow the appropriate authority’ (Entwistle, 2000: 232) and convey economic and cultural capital.

\section{Fashion and visibility}

The practice of dressing up, is not only driven by the public nature of the space however, it is also concerned with an individual's visibility in that space; the degree to which an individual feels scrutinised by others. In her discussion of dressing up Tseëlon argues that visibility is determined by the presence of a significant audience 'whose opinion and judgement matter' and which creates a less secure, less comfortable, environment where one feels 'on display, on show' (1995: 55). When in the company of these audiences women make much more of an effort with their appearance, as they are more likely to worry about their clothing when they feel they are 'being judged or when feeling insecure' (1995: 55).

This anxiety over visibility, is clearly demonstrated by a number of participants, including Diane. Aged 41, Diane is a single mum of two, who describes herself as having a 
'working class background' due to her parent's occupation and lack of home ownership. Her job as a receptionist at a secondary school means that she is often invited on staff trips, and she talks about how she worries about dressing up for these occasions.

Diane: I find things like that [staff trips] really difficult to know what to wear ... so I tend to go boring, black and white or you know something really safe, ... things that are neutral-ish, so it doesn't matter if the do is slightly posher. I went to the Theatre Royal, I agonised over what to wear for that. I had a black skirt, which is almost ankle length and it's just got a few round silver beads about 2 inches up from the hem... so I wore that with a dark top. And I felt smart enough to go, but I thought, 'I won't stand out, I won't look too over dressed, even if they all turned up in jeans,' which half of them were, but I felt okay. ... I think if I went out to these things a lot more I probably wouldn't [worry] so much because you kind of know what to wear, but I think because I don't go out that much I do get stressed. [Aged 41, School Receptionist]

Here the act of dressing up is driven by the public nature of the theatre, but Diane's anxiety is also influenced by her degree of visibility. She deems the audience as significant, their opinions and judgements matter, and she is anxious to dress in a way which will create the right impression and which communicates the right cultural knowledge.

But, Diane's comments also raise the issue of social class, because arguably it is due to her working class background that she does not have the relevant cultural capital to know what to wear or how dressed up to be. By her own admission, she is unsure of how to dress on these outings because they are unfamiliar to her, and therefore she does not have a 'feel for the game' (Bourdieu, 1990: 66). Instead she feels visible and anxious and uses clothes as 'armour against an uncomfortable situation' (Tseëlon, 1995: 61), choosing garments that she considers neutral, to 'blend in'.

\section{Perceptions of visibility}

Diane's discussion highlights an important class variable in the continuum of public space 
and visibility. As Bourdieu's work suggests, class can have an important influence on our cultural knowledge of spaces, such as the theatre, but it can also affect our perception of space and our sense of visibility. In Distinction (2005 [1984]) Bourdieu argues that the middle class have a 'Berkeleian vision' of the social world, which centres on the way in which they are 'perceived to be' (2005 [1984]: 253). 'Committed to the symbolic', he argues that they are 'haunted by the appearance [they] offer to others and the judgement they make of it' (2005 [1984]: 253). So perhaps it should come as little surprise that middle class women in this study seemed more inclined to perceive any audience, beyond their immediate friends and family, as a significant one, and thus any public space as one which requires some form of dressing up.

For Valerie and Veronica, for example, once outside the front door, or even in the company of visitors in their own homes, they feel they need to make a performance. Concerned that they will be seen by someone, indeed anyone, they exhibit a 'fear of exposure' (Thibaud, 2001: 42), an anxiety about being judged and consequently even in the context of routine, arguably 'less important stuff', such as visiting the supermarket, they feel it important to ensure that they are suitably and appropriately dressed (up).

Valerie: ...I do have stuff that I would be embarrassed to open the door in, but generally I try not to wear those clothes. Day-to-day I'd be wearing something similar to what I've got on [Bootcut jeans, a white cotton v-neck blouse, cotton scarf and wedged open toe sandals]. Certainly if I was going to Sainsbury's I'd wear this. But there are something things that I would wear in the house that I wouldn't go out in, like tracksuits and t-shirts, things that you shouldn't wear, or pyjamas [laughs]...I wouldn't wear them out of the house. [Aged 32, Legal Secretary]

Veronica: [At home] I'd be in jeans and a jumper, ...if I was leaving the house then I would change, if I was seeing friends I would change, in fact if I was seeing anyone. [Aged 55, HR Manager] 
So concerned by their visibility, or what Bourdieu terms 'seeming' (2005 [1984]: 200), it appears that these women are keen to maintain a level of dressing up almost all of the time. There is a clear desire to be seen 'in a good light' (253), and consequently they consider it vital to sacrifice those clothes which are seen to be at odds with the impression they are trying to give. Indeed, several participants acknowledge that they have clothes which they will only ever wear in private, and like Jessica, they often 'forgo or conceal action' (Goffman, 1990 [1959]: 50) which conflicts with their desired presentation of self, by hiding away and refusing to open their front door.

Jessica: I have clothes that I would only wear in the house, and if I was wearing them and someone came to the door I just wouldn't answer it.

Lucy: Yeah I'm like that... my husband will say the lads are coming round and I'll be like, 'Oh my God! They can't see me in my bright pink velour pants!'

Jessica: But I haven't got that many clothes that I wouldn't wear and I'll naturally be out most days anyway, so I get dressed every day, and in the evening if I know that I am not going out I'll just put my pyjamas on.

ucy: Yeah that's what I'm like... Like I'll probably put the pink trousers on after you've gone but I won't be seen dead outside! [laughs].

[Lucy: Aged 31, HR Manager/Jessica: Aged 30 Civil Servant]

Notably, within this discussion of private dress, pyjamas, as well as other lounge wear such as tracksuit bottoms, are often cited as examples. Worn only in private spaces, where these women feel invisible, these clothes are seen as a form of attire which is inappropriate for everyday public encounters, because of their symbolic meaning and their class associations.

A 'cultural practice as well as a symbolic product' (Kawamura, 2005: 32), fashion not only communicates attributes of the person, it operates as a wider symbolic representation of a society's social norms and cultural understanding. Derived from the Hindi word, Paejama, meaning leg covering, pyjamas were originally a loose trouser tied at the waist. Worn by men 
and women in Asia and the Middle East, they were colonialized by the British in the 1870s and were soon teamed with a shirt style top to form a 'sleep suit', worn by men instead of a nightshirt. By the 1930s, pyjamas were opened up to women and became a form of evening wear and lounge dress, to be worn at home and in bed (Cumming, et al., 2010) and since then, they have taken various guises including palazzo pants and more recently the onesie.

Though increasingly fashion designers and a small number of media commentators have suggested that pyjamas can be worn in public, and even to work (see Chilvers, 2012), it seems that for the middle class participants, pyjamas are still very much associated with the home and the bedroom, and are only suitable for invisible, private spaces. But perhaps just as important as the cultural understanding and history of pyjamas, are middle class women's views on the class connotations of wearing pyjamas in public, for it seems to be commonly viewed that wearing pyjamas in public is symbolic of working classness and lack of respectability.

In her continued discussion of the pink velour pants, for example, Lucy suggests that these are the types of clothes 'a council estate [woman] would go out in,' and that for working class women 'it would be a form of dressing up', whilst Jane and others tells me that you can identify working classes because 'they don't seem to have a sense of what is formal or informal' and can often been seen wearing 'sportswear in the street'. There is a keen desire, therefore, amongst these participants to avoid being seen in these types of dress in order to distance themselves from any working class evaluations, and a perceived lack of cultural and social capital.

Chloe: I'm not the kind of person who would wear tracksuit bottoms I just wouldn't wear them, I just can't do it. I live quite near Croydon and girls are like buffed out in tracksuits, with like slicked back hair I just think they look disgusting. I know that's really bad! [Laughs] I just think you get some perception about them when they wear clothes like that. That they're pikeys and they're just not nice people... 
$\mathrm{XX}$ : What do you mean by pikey?

Chloe: Common and rude, and not very good manners...just, I think there is a certain amount of class that people should have like if girls are going about in tracksuit bottoms and trainers they just don't really match up to standards,... I know it's really bad to think that but you see them and you think, 'oh they're pikeys.' [Aged 18, Student]

As Imogen Tyler (2008) notes, as class has become more political and complex, and as traditional markers of class have become increasingly eroded, a new vocabulary has emerged. The 'Chav' for example, and its 'various synonyms and regional variations' including 'pikey' (2008: 18), have made class differences and antagonisms explicitly visible and, as Chloe's comments suggest, it is often fashion practices, such as wearing tracksuits and 'private' dress in public spaces, which operate as class markers (Haywood and Yar, 2006).

Consequently, it seems that middle class preoccupation with 'seeming', is greatly motivated by a desire for class distinction. As Bocock (1998) and others suggests, class is about demarcation and difference, and instead of aspiring to look like those higher up the classes, these women profit from distancing and differentiating themselves from working classness. Motivated by their commitment to the symbolic and their anxiety over how they are perceived to be, they make constant and conscious efforts to avoid any perceived working class indicators and look to maintain the standards of middle class appropriateness and respectability, which, like other middle class values, have become the widely accepted norm (Skeggs, et. al, 2007; Skeggs and Wood, 2008; Savage, 2000).

Moreover, Chloe's remarks regarding 'nice people' indicate that alongside these values come moral judgements. To be seen as a 'good person' individuals are expected to follow the relevant (middle class) dress code, or run the risk of being seen as lacking moral virtue. As McDowell (2007: 136) argues, today 'class is a symbolic representation based on forms of moral value and specific dispositions that are neither equally accessible not similarly 
valued'. In social situations and social spaces there are 'specific rituals' and 'rules of behaviour', which are legitimised by middle class culture, and in order to ensure that individuals 'are seen to be of 'sound character' and 'reasonable' competence' these expectations need to be fulfilled (Crossely, 1995: 139). Our routine daily practices, work to 'exclude and segregate categories of people... by embodying in visible and tangible ways the cultural meanings variously ascribed to them' (Gieryn, 2000: 474). Failing to meet middle class norm, classifies individuals as deviant and thus morally wrong, and as a result working class performances are viewed as inappropriate and read as representative of a poor moral character.

\section{Dressing up and motherhood}

Moreover, it seems that for those who identified as middle class, the notion that one should 'maintain standards' is not at all compromised by motherhood. Indeed, several of the participants note that it is still important to 'make an effort' despite the fact that they have less time. Although some acknowledge that practicality and comfort are high priorities, they are still keen to ensure that their dress demonstrates a good degree of thought and care. For Lucy, Jessica, Valerie, Julia and Elizabeth, all of whom have young children, it remains important to dress up even though they are busy mums. And although this practice is partly driven, as Elizabeth suggests, by a desire and/or need to be seen in roles other than that of a mother, as Julia's remarks it is also motivated by a desire for class distinction, creating distance from working classness and the moral judgements with which is it associated.

As Finch (1993) notes there is a clear associate made between appearance and manner. Being deemed as 'chavy' mum is to be seen as a working class mum: a mother lacking in respectability who is dangerous, careless, irresponsible and selfish (Gillies, 2007: 
27), as opposed to a middle class mother whose practices are considered legitimate, appropriate and normal (Lawler, 2000).

Elizabeth: At work... I am trying to make an impression... for client meetings or I am just in the office. Your clients need to forget that actually what you're thinking about is your baby, you need to completely focus on them, so I suppose a long black coat or something semi-fitted, but very smart looking something that makes you look more streamlined... and professional. [Aged 42, Designer] Julia: When you've been off work and you've got a baby... comfort become vital, key. But I would still say I didn't want to lose my identity. I still wanted to dress up... I would still get up in the morning and get dressed, I wouldn't stay in my pyjamas all day and I'd still put a bit of make up on. I didn't want to be a chavy mum. [Aged 35, Business Analyst]

These attitudes however, are markedly different from those who identified as working class, many of whom see being a mother as fundamental to their social identity and an important factor in terms of visibility. For many of the working class participants their time is divided up between the weekends when they 'go out' and the rest of the week when they are 'at home with the kids'. Being at home does not simply refer to being in the private space of the house however, it includes being engaged in domestic tasks, such as the school run, grocery shopping and housework. These are spaces in which they are identified as mothers and thus do not require a performance. As Joy explains, ‘because we are mums... we don’t have to get up every morning and spend two hours doing hair and make-up'. Rather, in the context of 'home', the priority is that clothes are practical and functional and they consider themselves 'invisible' and not subject to scrutiny and judgements. Whereas it is important when 'going out' to dress up, 'at home' far greater priority is given to 'being' (2005 [1984]: 200).

Kim: I just bung something on in the morning, get them to school... I've got jeans that I'll wear every day and jeans that I wear out... The jeans I wear every day I wear with either flat shoes or trainers... You can't do high heels with kids, you know, you'd be 
staggering about all over the place, so it's either flat shoes like this [ballet pumps] or trainers during the day, but then of a weekend if I'm going out I'll wear the winkle picker boots, or shoes, or high heels or something you know. I have two different lives. During the week I feel I'm a mum, during the week I don't get time to do hair and make-up, I don't have time to bother with myself. But if I was dressed up, instead of being a mum, I'm me, and I'm doing it for me. [Aged 33, full-time Mother]

In terms of the daily routine, Kim regards the spaces in which she lives as invisible space, whether she is going to the local shops, the market, seeing neighbours or visiting friends. When identified as a mother, the requirement is simply to be clothed rather than dressed, and she, like other working class participants, does not have the same anxieties about opening the door dressed in pyjamas, or visiting supermarkets or the school gates in tracksuit bottoms and trainers. In fact, on a day-to-day basis when fulfilling routine domestic tasks, these are precisely the types of clothes she chooses to wear because they are more practical.

Kim: I have tracksuit bottoms and t-shirts, ... if my neighbours come round, or if it's a nice day I'll sit outside in them, and whoever comes round will see me in them...I'd run down to the local shops... [Aged 33, full-time Mother]

Joy: Well I have my slobbing around clothes and my going out clothes, and I'll go out in both because sometimes you have no choice... If I am with the baby and I'm looking...bad, I think people look at me and think, 'Oh she looks awful, but she's got a baby', if I went somewhere without the baby I would be more self-conscious, because they wouldn't know I had a baby, ... with the baby I have something to hide behind. I have an excuse. [Aged 19, Fast Food Restaurant Worker PT] Mandy: I think I'm more worried about what people think when I am out clubbing than what they do day-to-day, because you know I've got two kids so you know if I look like crap, I've got an excuse ... [Age 21, full time Mother]

Clearly then, there is a difference in these mothers' attitudes towards visibility in respect to their local audiences. Whilst some respondents feel that there is some need for pretence, even in daily domestic interactions, for others their mothering role negates the obligation to dress up. 
There may be a number of reasons for this. In her discussion of working class women and respectability, Skeggs (1997) argues that as her participants got older and had families, 'the space and time to act out femininity was more limited and trivialised in relation to their family responsibilities and economic worries, and could barely be justified' (1997: 108). Similarly Coopey, O'Connell and Porter suggest that life as a working class woman is 'as much time constrained as it is cash constrained' (2005: 99) and therefore there is not the time to dress up. But whilst it may be true that 'family responsibilities' leave less time for dressing up, this does not appear to be the only reason that these working class women feel that there is less of a need for a performance. Rather there appears to be important differences in attitudes towards motherhood and the priorities which it brings.

Walkerdine et al, (2001) and Skeggs, et al. (2008) both suggest that working class women tend to adopt much more 'traditional modes of femininity', which value good parenting and place it in 'opposition to aspiration and social mobility' (2008: 13). As a result, 'making material and domestic sacrifices for the family' are viewed as morally 'the right choice' (2008: 13), and it is important for mothers to be seen putting their child's needs first, before their own. In terms of dressing up day-to-day, perhaps it is deemed more important for women to fulfil their caring responsibilities and to prioritise the needs of their children and family, rather than spending the time on themselves and getting dressed up. As Joy clearly remarks, on an everyday basis she does not have time to spend on herself because she is a mother and the needs of her son have to come first. Although she might 'look bad' as a result, Joy feels that others will be able to see that she has fulfilled her role as a 'good mother' and for her that is more important.

\section{Neighbours as 'semi-private' spaces}

Differing attitudes towards motherhood fail to fully explain however, why a large proportion 
of the women who classified as working class, still exhibit different opinions regarding visibility to their middle class counterparts whether parents or not. Though only Becky admits that she visited her local newsagent in just her nightdress, there is a general feeling amongst the working class participants, that dressing up is not necessary when visiting their local shops, because this does not constitute 'going out'. They know the people there, they do not feel scrutinised or judged by them, and thus they are invisible.

Kelly: If I'm going out I'll put effort in, but if I'm going just round here I'll just wear tracksuit bottoms and just a top... because I know everyone and I know everyone's the same as me, because it's just a little area you don't get to see many people, so I wear just anything. [Aged 18, Unemployed]

Yvonne: I'm a dressy person, but I have to be casual because I don't go nowhere really, you know... I would wear like a jeans, jeans and a t-shirt or a shirt... I'm only getting dressed up if I'm going out. [Aged 47, Care Worker]

Goffman (1990 [1959]: 128) notes that 'in working class quartiers in Paris in the early morning, women feel they have the right to extend their backstage to their circle of neighbouring shops, and they patter down for milk and fresh bread, wearing bedroom slippers, bathrobe, hair net and no-make up', and it seems to a large extent a similar practice is operating here. '[U]nlike the middle classes, who have a degree of anxiety about external appearances (Bourdieu, 2005 [1985]: 201), Kelly, Yvonne and others do not demonstrate the same level of concern about the audiences they face locally, day to day. Rather whilst 'at home' they concern themselves mostly with being. Their clothes are practical, functional and cheap, consisting mainly of jeans, t-shirts, tracksuit bottoms and trainers, and they worry little about creating an impression for others or being 'caught out'. Comfortable with 'extending their backstage' beyond the confines of their home, they are content with being seen in forms of private or invisible dress, including pyjamas within these spaces. 
Contrasting with the attitudes of the middle class participants, they raise questions as to what extent spaces such as local neighbours and corner shops, constitute private spaces for these women. For although they are not spaces which are privately owned, they are spaces which are often inhabited by friends and relatives and are to some extent perceived as extensions of the home. In his discussion of urban space, Madanipour (2003) suggests that neighbourhoods can constitute 'semi-private' spaces. An inter-personal realm, he argues that the boundaries of the neighbourhood can potentially intensify the encounters between its residents and as a result 'the possibility of privacy and concealment is reduced' (2003: 162). This means that the neighbourhood can intrude into the private sphere of the individual and household, and at the same time the neighbourhood can become an extension of the private sphere of the individual and the home. Just as Kelly suggests, within the context of the housing estate she knows everyone and everyone knows her. Therefore there is no need for a performance, as the neighbourhood is an extension of her private space. But if she goes beyond the boundary of the estate Kelly ensures that she 'dresses up', as this constitutes 'going out' into a public space where she is likely to encounter strangers.

This view, is also demonstrated by Kim, who says that although she wears tracksuit bottoms and trainers day to day, in front of neighbours and to the local shop, she will not wear them 'out on the street' where people do not know her, because of the judgements they might make. And similarly Angie tells me how she smartens up if she is 'going out' clothes shopping, for drinks or dinner although day to day she doesn't go far from home, so there is no need to dress up.

Kim: I wouldn't out on the street where people don't know me, for them to think, 'what's she got on?' [Aged 33, full-time Mother]

Angie: Look at me, in my rags... Well if I'm not going nowhere, then baggy t-shirts and ripped up trousers and things, if I'm doing the garden. I'd smarten up a bit to go to [Brixton] market, it sounds ridiculous. I don't dress up to be round the house, ...but going 
out, going out for drinks or a meal then I'd wear a skirt and shoes, you know, not the trousers. [Aged 54, full-time Mother]

For these women local spaces outside of their home do not carry the same demands in terms of dressing up, as they do for the middle class participants. As Bourdieu (2005 [1984]: 201) argues they lack the same concern over 'formality and formal dress in the domestic world, the place of freedom' and consequently, 'scarcely mark a distinction between top clothes, visible, intended to be seen and underclothes, invisible or hidden'.

\section{Dressing up and going out}

Yet, that does not mean, as Bourdieu seems to suggest, that these women are not engaged in dressing up. Though chiefly concerned with being during the week, at the weekends when these participants 'go out' to pubs and clubs, in the local towns and city they are very concerned with dressing up and creating a 'personal front'. Unlike their local neighbourhood, the audience in these spaces, is 'unfamiliar' and more 'significant', it is a more visible, public space. These are spaces in which the participants feel more self-conscious and subject to scrutiny, and it is important to dress up and make an impression.

Trisha: [at home] you're just in jeans and a t-shirt, but obviously you go out to impress don't you, or try anyway, so I like to feel good and I like to look sexy, but not tarty, just nice and attractive. [Aged 43, full-time Mother]

In dressing up for these occasions immense effort is put into getting ready to 'go out'. In some cases dressing up takes up to 3 hours: putting on make-up, doing their hair, putting on false finger and toe nails, adding in hair extensions and applying fake tan. They ensure that they have something new to wear, and their dressing up clothes are considered more revealing, smarter, detailed, colourful, and conspicuous; significantly different from their everyday. 
Joy: Normally... I don't bother, so when I get dressed up people are like, 'Wow!' [Aged 19, Fast Food Restaurant Worker (PT)]

Kim: When I do dress up, when I do go out... I do my hair and make-up... the false nails go on, everything... spray tan, hair extensions, false nails, false eye lashes... [Aged 33 full-time Mother]

Mandy: On a day-to-day basis I pick my clothes out just randomly, it takes me about half an hour. When I am going out, ...it will take me about 2 hours to decide what I am wearing and that's not like [including] having a bath, doing my make-up, ... that's just choosing my clothes. [Aged 21, full-time Mother]

As Skeggs (1997: 106) found, going out provides these women with a 'reason for dressing up', and while dressing up is more infrequent, the public performance is no less important to them. In fact, in many respects because dressing up occurs much less frequently, it requires much more time and effort, and perhaps this too is part of the reason why it takes place much less often. Indeed, the planning and preparation that goes into dress up is enormous, and in most cases, the women spend the time leading up to the event thinking about how they will dress, and often shopping for something new.

Angie: I'm going to a party soon, at the end of the month... I'm going to buy something new for that. Because that's a friend's fortieth, and the friend that I'm going with has seen me in everything I go out in. So I'm going to look for something new. [Aged 54, full time Mother]

Lisa: If I've been told in advance that a special occasion is coming up... you know it's going to be expensive... I'll save up so that I can get a good outfit, and then I'll go shopping. But if it's just like going out, like a night out on the town, then I'll decide like the week before. [Aged 26, full-time Mother]

As Angie and Lisa's remarks suggest, the significance of these events is further underlined by the fact it is important to wear something new which the audience has not seen before. This is highlighted in the comments from Mandy below, which demonstrating just how significant these weekend audiences are for these women, and how visible the space is in comparison with the local spaces they encounter day-to-day. 
Mandy: I don't like to go to the same place wearing the same stuff that I've worn before... Even though I may never the see the same people there again, I always get that feeling that, 'she wore that last time she was here,' you know what I mean? So, you know, I always have to have something new... [Aged 21, full-time Mother]

For Mandy there is much greater anxiety over how the audience may view her in these spaces. Even though she may never see these people again, it is vital to make a 'good impression' and she feels she will be judged negatively if her audience notices that she is not wearing something new. Focusing on her appearance is a way of dealing with the stress and anxiety over how she will be judged. By wearing something new, she feels that she looks good and is more confident in an environment in which she feels more visible and more scrutinised by others. Arguably again though, this anxiety over public performance, and the heavy attention to detail is driven at least in part by class position.

Tseëlon (1992) argues that the more insecure a woman feels the greater the attention paid to their clothing and appearance, and it would seem that working class women would be more likely to feel insecure as they do not know the rules of the game. As Skeggs (1997) suggests, respectability, determined on the basis of appearance and manner, is constructed within the context of middle class values, and therefore it does not 'fit' working class women. As Kelly comments show below, working class women are aware of the ways in which they are judged by others, and therefore when going out, they take great pains to dress up and ensure that they look their best, so that they can meet the expectations of those around them.

Kelly: I could go into Croydon and buy a $£ 10$ dress and look as good someone else who spent $£ 500$ on a dress, it just depends how much you try because if I saw someone who I thought was posh yeah, I'd just have to think about it from the way that they dressed, and I'd think just looking at someone like that I'd think, 'oh they're posh, they live in a big house, '... I do think that some people who have loads of money when they see people like myself, they turn their nose up a bit because they think we don't have much money we're not [good enough], do you know what I mean? 


\section{Conclusion}

Though traditionally fashion theorists have placed important emphasis on fashion's relationship with public space and visibility as a way of explaining its relationship to class, in recent years the association between fashion, class, gender and space has been largely overlooked. Yet increasingly, it is through cultural practices, such as dressing up, that class distinctions are drawn. And, in many ways, being seen in your pyjamas is useful example of the way in which class is made through 'active, ongoing and negotiable ... practices that vary across time and space' (McDowell, 2008: 21).

An important means of class distinction, being seen in your pyjamas, appears to embody differing class attitudes to visibility and perceptions of public space, whilst operating a mechanism for class evaluations. Arguably a classed disposition, it indicates the degree to which one feels scrutinised in a particular social context or space, it highlights differences in women's anxiety over how they appear to others, and it emphasises distinctions in women's notions of appropriate dress and the extent to which a performance is deemed necessary.

For the working class women in this research, being dressed in your pyjamas, in the context of the everyday, the school run or the weekly shop, is not a concern. There no-one to dress up for here, no impression to be made, because 'everyone knows everyone'. The women in this study, deem their neighbourhood audience as insignificant: their opinion and judgements do not matter and therefore in these inter-personal and semi-privates spaces, backstage performances can extend. Moreover, for those who are mothers, it is important that their time is prioritised in terms of their children's needs, rather than 'dressing up', and they feel that being identified as a mother affords them some degree of understanding or leniency in terms of their dress.

That is not to say that working class women never dress up. Though Bourdieu (2005 [1984]) may claim that the working class simply have a taste of necessity, today dressing up 
is clearly an important and regular activity for working class women in the UK. But it is one which takes place in the context of 'going out', where these women will encounter strangers, whose opinions matter a great deal. Indeed, dressing up for these occasions is highly important and it is a practice which requires immense time and effort.

For the middle class participants however, concern over how they might appear to strangers is experienced much more commonly, because for these women there is a greater awareness of judgements others make, even in ordinary contexts. Consequently, they have a far greater need for pretence, constantly aware of evaluations that might be made of them. As a result, they find some level of dressing up necessary in almost any social space, and even in their own homes can experience some degree of visibility.

For these women, being seen in your pyjamas would be unspeakable; a form of private dress suitable for personal and intimate spaces, pyjamas are deemed totally inappropriate for public and visible contexts. Moreover, deemed indicative of working classes, who fail to adhere to the standards of respectability, being seen in your pyjamas is to be avoided at all costs, even if this means not answering the front door.

Whether it is in the context of the everyday, or 'going out', the women in this research clearly demonstrate that dressing up is about putting on a show and creating a public image. Dressing up is about clothes which are visible, used to communicate and evaluate social identities. But while there are some common understandings across the classes as to what dressing up is, there is less consensus over when and where it is needed, and being seen in your pyjamas is perhaps an important way in which this class distinction is mobilised.

\section{Acknowledgements}

\section{Notes}

1. Though there is an imbalance between the numbers of working class and middle class participants in this study, this was largely because respondents were not asked directly about their class location or occupation before they were recruited to the project. 


\section{Notes on contributor}

Having completed an Undergraduate Degree in Sociology with Law, and a Masters in Social Research Methods at Durham University, I embarked upon a PhD in the Sociology of Fashion at the London College of Fashion University of the Arts London. I completed my PhD in November 2011, under the supervision of Dr. Joanne Entwistle and Dr. Agnés Rocamora.

My research looks at the relationship between fashion and class in regards to the practices and discourses of British women today. It identifies key class distinctions in relation to perceptions of public space and notions of femininity and important differences in women's attitudes towards fashion and their buying practices. In addition, the research highlights the importance of the motherdaughter relationship in cultivating classed tastes and fashion habitus, and notes the both the unconscious and long lasting nature of early learning. The research has generated a number of avenues for further investigation, particularly in relation to motherhood, space and fashion performances.

Alongside my research I have been lecturing in Sociology and Cultural and Historical Studies at Kingston University London and the London College of Fashion. I have been working at Kingston University London for over 6 years now, and have designed and led courses which explore fashion's role in the consumer society, and its relationship to social identity.

\section{References}

Xxxx (2012) Classifying Fashion and Fashioning Class. PhD Thesis, London College of Fashion, University of the Arts London

Ardener, S. (1997) Woman and Space: Ground Rules and Social Maps. Oxford; New York: Berg

Barnard, M. (2010) Introduction. In M. Barnard (ed.) Fashion Theory: A Reader. Oxford; New York: Routledge

Bell, D., Binnie, J., Cream, J., and Valentine, G. (1999) All Hyped Up and Nowhere to Go. Gender Place and Culture 1(1): 31-47

Bennett, A. (2005) Culture and Everyday Life. London: Sage

Bocock, R. (1993) Consumption. London: Routledge

Bottero, W. (2005) Stratification: Social Division and Inequality. Oxon: Routledge

Bourdieu, P. (1990) The Logic of Practice. Cambridge: Polity

Bourdieu, P. (2005) [1984] Distinction: A Social Critique of the Judgement of Taste. London: Routledge \& Kegan Paul 
Breward, C. and Gilbert, D. (2006) Fashion's World Cities. Oxford: Berg

Chilvers, S. (2012) Is it ever okay to wear pyjamas to work? The Guardian Thursday 15

March 2012 http://www.theguardian.com/fashion/fashion-blog/2012/mar/15/ever-okwear-pyjamas-to-work Accessed: 2 July 2013

Coopey, R., O’Connell, S. and Porter, D. (2005) Mail Order Retailing in Britain: A Business and Social History. Oxford: Oxford University Press

Craik, J. (1998) [1993] The Face of Fashion: Cultural Studies in Fashion. London: Routledge

Crane, D. (2000) Fashion and Its Social Agenda: Class, Gender, and Identity in Clothing. Chicago: University of Chicago Press

Cresswell, T. (1994) Place: A Short Introduction. Oxford: Blackwell

Crompton, R. (1998) Class and Stratification: An Introduction to Current Debates. $\left(2^{\text {nd }}\right.$ ed.)Cambridge: Polity Press

Crompton, R. (2008) Class and Stratification. ( ${ }^{\text {rd }}$ ed.)Cambridge; Malden, MA: Polity

Crossley, N. (1995) Body Techniques, Agency and Intercorporeality: on Goffman's relations in Public. Sociology 29(1): 133-149

Cumming, V., Cunnington, C. W. and Cunnington, P. E. (2010) The Dictionary of Fashion History. Oxford: Berg

De Grazia, V. and Furlough. E. (eds.) (1996) The Sex of Things: Gender and Consumption in Historical Perspective. London: University of California Press

Devine, F. and Savage, M. (2005) The Cultural Turn, Sociology and Class Analysis. In F. Devine, M. Savage, J. Scott and R. Crompton (eds.) Rethinking Class: Culture, Identities and Lifestyles. Basingstoke; New York: Palgrave

Devine, F., Savage, M., Scott, J. and Crompton, R. (2005) Rethinking Class: Identities. Cultures and Lifestyles. London: Palgrave

Entwistle, J. (1997) Power Dressing and the Fashioning of the Career Woman. In M. Nava, I. MacRury, A. Blake and B. Richards (eds.) Buy This Book. London: Routledge

Entwistle, J. (2000) Fashioning the Career Woman: Power Dressing as a Strategy of Consumption. In Andrews, M and Talbolt, M.M. (eds) All the World and His Husband: Women in Twentieth Century Consumer Culture. London: Biddles Ltd.

Entwistle, J. (2000) The Fashioned Body. Cambridge: Polity

Entwistle, J. (2001) The Dressed Body. In J. Entwistle and E. Wilson (eds.) Body Dressing. Oxford: Berg 
Entwistle, J. (2009) The Aesthetic Economy of Fashion: Markets and Value in Clothing and Modelling. Oxford; New York: Berg

Featherstone, M. (1991) Consumer Culture and Postmodernism. London: Sage

Finch, L. (1993) The Classing Gaze: Sexuality, Class and Surveillance. St Leonards, NSW, Australia: Allen and Unwin

Gieryn, T. F. (2000) A Space for Place in Sociology. Annual Review of Sociology 26: 4634496

Gillian, R. (1999) Performing Space. In D. Massey, J. Allen and P. Sarre (eds.) Human Geography Today. Cambridge; Oxford: Polity Press

Goffman, E. (1990) [1959] The Presentation of Self In Everyday Life. London: Penguin

Gunn, S. (2000) The Public Culture of the Victorian Middle Class: Ritual and Authority in the English Industrial City 1840-1914. Manchester: Manchester University Press

Hebdige, D. (2006) [1979] Subculture: the meaning of Style. London: Routledge

Hetherington, K. (1998) Spaces of Identity: Space, Performance and Politics. London: Routledge

Jones, O. (2011) Chavs: The Demonization of the Working Class. London: Verso

Kawamura, Y. (2005) Fashion-ology. Oxford; New York: Berg

Lawler, S. (2000) Mothering the Self: Mothers, Daughters, Subjects. London; New York: Routledge

Löw, M. (2006) The Social Construction of Space and Gender. European Journal of Women's Studies 13(2): 119-133

Lynch, A. and Strauss, M. D. (2007) Changing Fashion: A Critical Introduction to Trend Analysis and Meaning. New York: Routledge

Madanipour, A. (2003) Public and Private Spaces of the City. Oxon: Routledge

Massey, D., Allen, J. and Sarre, P. (1999) Introduction Part V. In D. Massey, J. Allen and P. Sarre (eds.) Human Geography Today. Cambridge; Oxford; Malden: Blackwell

McDowell, L. (1997) Capital Culture: Gender at Work in the City. Oxford: Blackwell

McDowell, L. (1999) City Life and Difference: Negotiating Diversity. In Allen, J. Massey, D. and Pryke, M. (eds.) Unsettling Cities. London: Routledge

McDowell, L. (2007) Spaces of the Home: Absence, Presence, New Connections and New Anxieties. Home Cultures 4 (2): 129-146

McDowell, L. (2008) Thinking Through Class and Gender in the Context of Working Class Studies. Antipode, 40 (1): 20-24.

Miller, D. (1998) Shopping, Place and Identity. Oxon: Routledge 
Nagel, T. (1998) Concealment and Exposure. Philosophy and Public Affairs. 27(1): 3-30

Payne, G. and Grew, C. (2005) Unpacking Class Ambivalence. Sociology 39(5): 893-910

Potvin, J. (2009) The Places and Spaces of Fashion. Oxon. Routledge

Rocamora, A. (2009) Fashioning the City. London: I.B. Tauris

Saunders, P. (1990) A Nation of Home Owners. London: Unwin Hyman

Savage, M., Devine, F., Cunningham, N., Taylor, M., Li, Y., Hjellbrekke, J., Le Roux, B., Friedman, S., and Miles, A. (2013) A New Model of Social Class. Sociology 47 (2): 219-250

Sennett, R. (2003) [1974] The Fall of Public Man. London: Penguin

Simmel, G. (1971) [1903] The Metropolis and Mental Life. In D. Levine (ed.) On Individuality and Social Forms. Chicago: Chicago University Press

Simmel, G. (2004) [1901] 'Fashion'. In D. L. Purdy (ed.) The Rise of Fashion: A Reader. Minnesota: University of Minnesota Press

Skeggs, B. (1997) Formations of Class and Gender: Becoming Respectable. London; Thousand Oaks, CA: Sage

Skeggs, B. (2004a) Class, Self and Culture. London: Routledge

Skeggs, B. (2004b) Context and Background: Pierre Bourdieu's Analysis of Class, Gender and Sexuality. The Sociological Review 52(s2):19-33

Skeggs, B. and Wood, H. (2008) Oh Goodness I am watching reality TV: How Methods make Class in Audience Research. European Journal of Cultural Studies 11 (1): -24

Skeggs, B., Wood, H. And Thumim, N. (2007) Making Class Through Moral Extension on Reality TV. Avaliable at: http://www.medfak.umu.se/digitalAssets/29/29326_workshop_intimacy_ahorarkop.p df; accessed 28 September 2010]

Smith, N. (2000) What happened to Class? Environment and Planning A 32: 1011-1032

Southerton, D. (2002) Boundaries of 'Us' and 'Them'. Sociology 36 (1): 171-190

Storr, M. (2003) Latex and Lingerie. Oxford: Berg

Tan, E. S. (2004) Does Class Matter? Singapore: World Scientific Publishing

Tarlo, E. (2010) Visibly Muslim: Fashion, Politics and Faith. Oxford: Berg

Taylor, Y. (2012) Fitting into Place? Class and Gender Geographies and Temporalities. Surrey: Ashgate

Thibaud, JP. (2001) Frames of Visibility in Public Places. Places 14 (1): $42-47$

Tseëlon, E. (1992) Self Presentation through Appearance: A Manipulative vs. Dramaturgical Approach. Symbolic Interaction 15 (4): 501-513 
Tseëlon, E. (1995) The Masque of Femininity: The Presentation of Woman in Everyday Life. London: Sage

Valentine, G. (2001) Social Geographies: Space and Society. Essex: Pearson Education Ltd Vinken, B. (2005) Fashion Zeitgeist: Trends and Cycles in the Fashion System. Oxford; New York: Berg

Veblen, T. (1994) [1899] Theory of the Leisure Class. London: Dove Publications

Walkerdine, V., Lucey, H., and Melody, J. (2001) Growing Up Girl: Psychosocial Explorations of Gender and Class. London: Palgrave

Walkowitz, J. R. (1992) City of Dreadful Delights: Narratives of Sexual Danger in lateVictorian London. Virago: London

Wilson, E. (2007) [1985] Adorned in Dreams: Fashion and Modernity. London: I.B. Tauris

Woodward, S. (2007) Why Women Wear What They Wear. Oxford: Berg 